\title{
Hibridismo e generosidade na poesia de Ondjaki
}

\section{Luiz Fernando Valente}

Brown University

Resumo: A poesia de Ondjaki celebra o híbrido em suas mais variadas formas, como a pluridiscursividade da língua portuguesa, a permeabilidade entre textos e autores, a quebra de nítidas fronteiras entre o humano e o natural e a contestação da posição privilegiada da razão. Ao fazê-lo, o poeta insere-se no que, em um ensaio sobre a escrita de Carlos Drummond de Andrade e de William Carlos Williams (2005), identifiquei como uma "poética da generosidade", a um tempo humilde e transgressora, que, na esteira de pensadores como São Paulo, São Francisco de Assis, Martin Buber, Paulo Freire, e Leonardo Boff, entre outros, busca repensar o mundo pelo viés de um dialogismo que coloca em questão os alicerces iluministas da modernidade baseada no racionalismo e no individualismo. No presente artigo, minha reflexão sobre o hibridismo encontra apoio teórico nos trabalhos recentes do historiador Dominick LaCapra, em especial History and its Limits. Human, animal, violence, publicado em 1999.

Palavras-chave: dialogismo, generosidade, hibridismo, limites, Ondjaki

Abstract: Ondjaki's poetry celebrates the hybrid in its various forms, such as the pluridiscursivity of the Portuguese language, the permeability between texts and authors, the breaking down of clear boundaries between the human and the natural and the contestation of the privileged position of reason. In doing so, Ondjaki inserts himself into what, in an essay on the poetry of Carlos Drummond de Andrade and William Carlos Williams (2005), I identified as a "poetics of generosity", at the same time humble and transgressive, which in the wake of thinkers such as Saint Paul, Saint Francis of Assisi, Martin Buber, Paulo Freire, and Leonardo Boff, among others, seeks to rethink the world through the optic of a dialogism that calls into 
question the origins of modernity in the rationalism and individualism of the Enlightenment. In the present article, my reflection on hybridity finds theoretical support in the recent work of historian Dominick LaCapra, especially in his book History and Its Limits. Human, animal, violence, published in 1999.

Keywords: dialogism, generosity, hybridity, limits, Ondjaki

\section{Introdução}

Admirado principalmente pela qualidade de sua ficção, o angolano Ndalu de Almeida (n. 1977), conhecido literariamente como Ondjaki, é também um excelente poeta, cujos seis volumes de poesia dialogam produtivamente com sua prosa, devendo ser considerados, portanto, em qualquer avaliação mais abrangente da sua obra. Este ensaio focaliza no livro Materiais para Confecção de um Espanador de Tristezas, publicado em 2009, que, em cinquenta e quatro textos, incluindo vários poemas em prosa, coloca de maneira muito original, tanto temática quanto tecnicamente, a questão do hibridismo.

A reflexão desenvolvida neste artigo encontra apoio teórico em alguns trabalhos do historiador norte-americano Dominick LaCapra, em especial seu livro History and Its Limits. Human, animal, violence, coincidentemente também publicado em 2009. Na "Introdução", LaCapra explica o propósito do volume em termos relevantes para nossa discussão:

\footnotetext{
A leitmotif of this book (and of much of my work) is how - and how not - to think about limits, both limits that bind or impose constraints, prominently including normative constraints that indicate when one is going too far, and the limits in the sense of the extreme or excessive event or experience that transgresses normative limits or suspends constraints and boundaries. (LaCapra 2009: 7)

[Um leitmotiv deste livro (e de grande parte do meu trabalho) é como pensar - e como não pensar sobre limites, quer sejam os limites que vinculam ou impõem restrições, incluindo proeminentemente restrições normativas que indicam quando se está indo longe demais, quer seja o limite considerado como evento extremo ou excessivo ou como uma experiência que transgride limites normativos ou suspende restrições e fronteiras].
}

LaCapra enfatiza, outrossim, a necessidade de "prestar uma contínua atenção ao problema crucial da interação real e desejável entre os limites e os desafios que os superam" 
["paying sustained attention to the crucial problem of the actual and the desirable interaction between limits and what challenges or exceeds them"] (LaCapra 2009: 7). O autor nos convida a repensar a historicidade das fronteiras que a civilização ocidental, especialmente em seu viés racionalista e iluminista, erigiu e normalizou como forma de controle e apaziguamento "objetivo" de subjetividades contestatórias que apontariam para a alternativa de uma "implicação ou envolvimento mútuo do observador e do observado" ["implication or mutual involvement of the observer and the observed"] (LaCapra 2009: 5). Ao refletir sobre a questão dos limites, LaCapra estabelece importantes pressupostos teóricos para uma conexão entre hibridismo e generosidade.

\section{Terminologia}

Como preâmbulo à discussão da poesia de Ondjaki, conforme proposta no título deste ensaio, seria útil considerar a etimologia dos adjetivos generoso e híbrido.

O adjetivo generoso é derivado de genus, indicando nobreza de origem. Assim seria menos algo que se aprende, como as regras de boas maneiras ou os preceitos de lealdade tribal, do que uma qualidade intrínseca aos seres humanos, talvez a expressão mais profunda de sua humanidade, noção que aparece no pensamento dos antigos estoicos e que seria futuramente incorporada ao pensamento cristão. Nesta linha, ser generoso é ser autêntico às nossas origens sagradas ou quase sagradas como seres humanos. ${ }^{1}$ Não surpreende, portanto, que, de São Paulo e São Francisco de Assis a Martin Buber e Paulo Freire, o conceito de generosidade tenha interessado a pensadores com uma visão religiosa do mundo. São Paulo (c.5-c.64) propõe na "Epístola aos Filipenses" que o cristianismo depende do ato supremo de generosidade do Deus que se faz homem. Essa lição de humildade e compaixão deve ser imitada não porque seria uma receita para a salvação, mas porque representa aquilo que, como Cristo se despindo da sua divindade para ser carne (kenosis), nos faz essencialmente humanos. Paulo chama a generosidade de caritas, que, diferentemente de eros, voltado para a satisfação do desejo individual, é o amor que se abre para o outro, conceitualização que desenvolve em maior detalhe na "Primeira Epístola aos Coríntios". Nesse sentido, generosidade não se presta a uma concepção utilitária do mundo, concebido como um conjunto de indivíduos distintos uns dos outros e voltados para suas 
próprias necessidades, mas aponta, ao contrário, na direção de uma comunidade de seres interligados por sua humanidade mais básica. Durante a Idade Média, o mais importante proponente da generosidade é São Francisco de Assis (1182-1226), fundador de uma ordem monástica incondicionalmente dedicada à pobreza e à caridade. Outros teóricos da generosidade cujo pensamento é de interesse para este artigo são Gottfried Wilhelm Leibniz (1646-1716), Martin Buber (1878-1975), Paulo Freire ${ }^{2}$ (1921-1997) e Leonardo Boff (n. 1938). Voltaremos às suas ideias mais tarde.

O vocábulo híbrido remonta a hybris, termo que remete à ideia de excesso, revelando a suspeita dos antigos gregos $m$ relação à mistura, considerada um ultrajante descomedimento ou uma violação das leis naturais. Como sabemos, o termo é frequentemente associado ao herói trágico, cujas escolhas moralmente falhas provêm de arrogância, orgulho ou rendição a paixões desenfreadas. À hybris se opõe a sophrosyne, isto é, a virtude da prudência, do comedimento e da medida certa. Essa oposição informa não só as tragédias de Ésquilo, Sófocles e Eurípedes, mas aparece também nos poemas homéricos, nos fragmentos de Heráclito e em alguns diálogos de Platão, como o Cármides e o Crátilo. O preconceito em favor da pureza, por oposição ao híbrido, perpassa a cultura ocidental, refletindo-se, por exemplo, na crença da suposta superioridade de animais de "puro sangue" ou, nefastamente, em injunções contra a miscigenação.

\section{Poesia impura}

Em tendência contrária a esse preconceito, a poesia "impura" de Ondjaki ("teias imperfeitas de uma aranha preguiçosa" - Ondjaki 2009: 28) celebra o híbrido nas suas mais diversas variações. Vejamos. Primeiro, a rica pluridiscursividade da língua portuguesa, com sua multiplicidade de dialetos e falares; Ondjaki demonstra enorme prazer em misturar vocábulos angolanos e brasileiros, ou combinar expressões coloquiais com o português padrão, colocando em questão a preeminência deste e, ao mesmo tempo, revitalizando-o. Segundo, a permeabilidade entre textos e autores; para Ondjaki, escrever - e, por extensão, ler, na medida em que a escrita é sempre uma releitura, enquanto o ato da leitura é também um processo criativo - é dialogar inevitavelmente com outros escritores, no seu caso sobretudo brasileiros e luso-africanos, como João Guimarães Rosa (1908-1967), José 
Luandino Vieira (n. 1935), Raduan Nassar (n. 1935), Adélia Prado (n. 1935), Carlos Drummond de Andrade (1902-1987), Mia Couto (n. 1955), Manoel de Barros (1916-2014), João Cabral de Melo Neto (1920-1999) e Graciliano Ramos (1892-1953). É isso que revela "Intimidar o poema a ser raiz", misto de arte poética e autobiografia literária, transcrito abaixo:

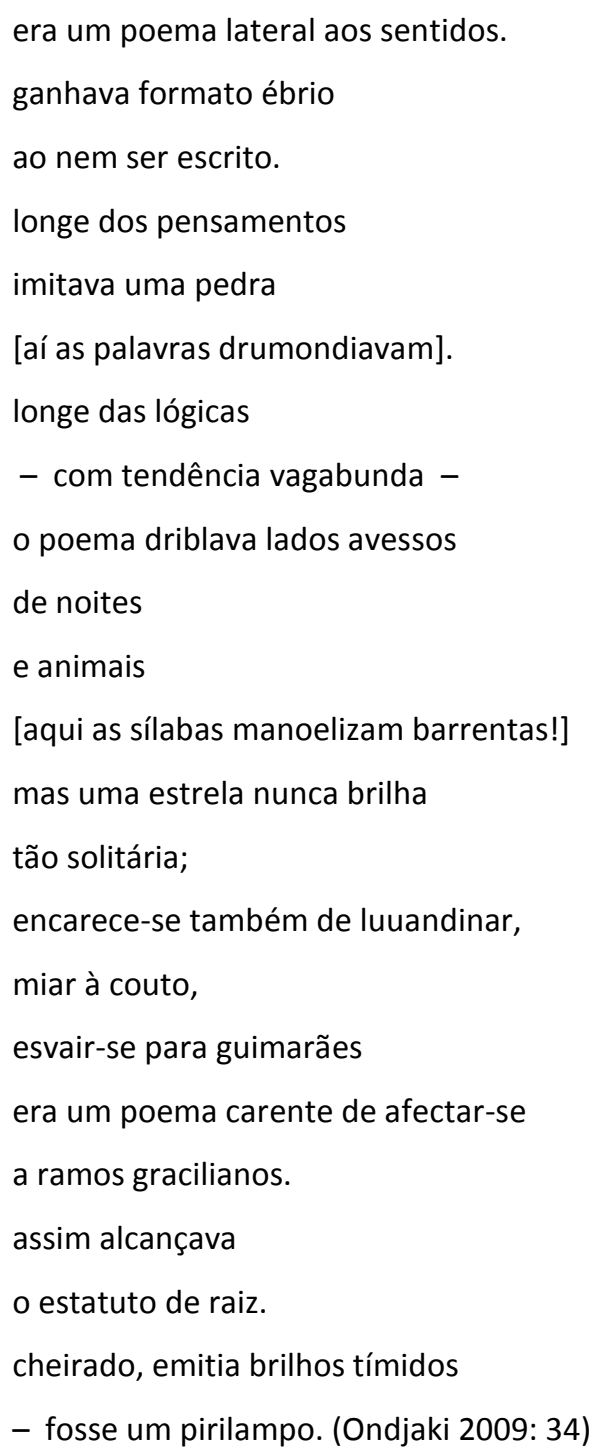

As referências aos escritores - inovadores que, da periferia ou quase-periferia, cruzaram as fronteiras da tradição para renovar o cânone literário lusófono - com os quais sua obra dialoga implícita e explicitamente não servem apenas para homenagear suas reconhecidas influências literárias, mas ajudam a delinear o que poderíamos chamar uma estética da lateralidade ("era um poema lateral aos sentidos"), na qual está "enraizada" sua 
poesia, como sugere o título. Questiona-se a posição privilegiada do que a civilização racional e utilitária considera como central, isto é, os padrões da ordem, do "bom senso" e da temperança, revelando, ao contrário, uma preferência pelo que é "normalmente" considerado marginal. Assim, a estética da lateralidade recusa a linha reta ("formato ébrio"), rejeita a distinção entre direito e avesso ("driblava os avessos"), contesta a prioridade da mente sobre o corpo ("longe das lógicas"), valorizando os sentidos como forma de apreensão do mundo ("cheirado, emitia brilhos tímidos"), e repudia a concepção do ser humano como um mero indivíduo ("uma estrela nunca brilha / tão solitária"), enfatizando, antes, a porosidade entre o eu e o outro ("carente de afectar-se / a ramos gracilianos"). Terceiro, a ruptura de limites nítidos entre o humano e o natural, mais especificamente entre os seres humanos e os animais. No mundo fluido e eternamente movente onde existimos, cada lugar corre o risco de se transmudar em um "deslugar", como indica o poema "Um lugar":

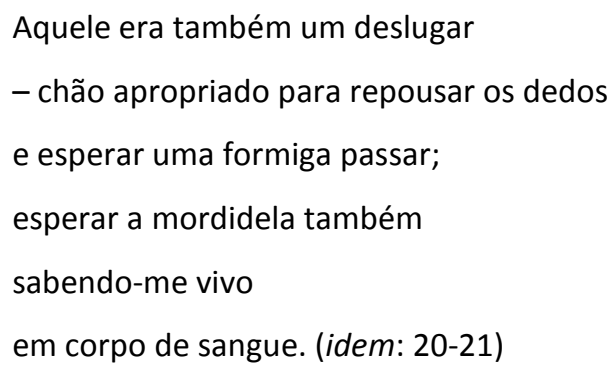

Essa fluidez permite que o poeta postule uma reciprocidade não hierárquica entre homens e animais. É exatamente isso que sugere "A garça e as tardes":

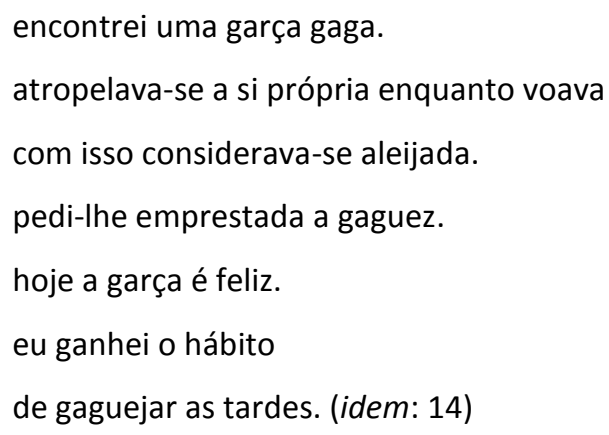


Finalmente, e reiterando o que foi dito acima, sua poesia contesta a posição privilegiada da razão na cultura ocidental. Ao fazê-lo, insere-se no que, em um ensaio comparativo sobre a poesia de Carlos Drummond de Andrade e de William Carlos Williams (Valente 2005: 7-19), identifiquei como uma "poética da generosidade", a um tempo humilde e transgressora, que busca repensar o mundo por um dialogismo que se abre para o outro, colocando em questão os alicerces iluministas da modernidade baseada no racionalismo e no individualismo. É nessa direção que aponta o prototípico "homem poeta" jorge palma no poema em prosa "Só": "propício à poesia, à música, ele inventava passos novos, suava os dedos, golpeava a lógica [grifo meu]. ele regressava - sem nunca ter saído da terra dos sonhos. cambaleava os pés em trejeitos de cuidado, usando os olhos de catarina pra iluminar um atalho musical" (Ondjaki 2009: 33). Mais uma vez o poema assume a sua "lateralidade" e o poeta é referido como "ébrio", por oposição ao mundo "normal" da racionalidade, da temperança e dos bons costumes. Essencialmente dissidente, a poesia pretende, pelo contrário, restabelecer ligações com uma ancestral e mais autêntica "terra dos sonhos", à qual se retorna não pela via da razão, mas por uma trilha repleta de meandros e iluminada pela arte. Como diz outro poema, "O vivenciado são as cores do céu quando não conseguimos / explicá-las e elas não esgotam o pensamento" (idem: 73).

Antirromântica por excelência, a poesia de Ondjaki se recusa a se constituir em uma expressão de um suposto eu profundo, anterior à escrita, ecoando o célebre verso de Drummond, "O que pensas e sentes, isso ainda não é poesia" (Andrade 2003: 117). Antes que um veículo para a expressão de um eu concreto ("quero falar com esse de mim que escreve / apaziguar-me através dele," (Ondjaki 2009: 28)), a poesia se despersonaliza em uma

\footnotetext{
construção de uma pessoa [do embrião aos livros] construção do amor construção da sensibilidade [desde os poros até à música] construção de uma ideia [passando pelo que o outro disse] construção do poema [e do sentir do poema] (idem: 81)
}

Essa concepção da poesia conecta Ondjaki com João Cabral, para o qual o texto poético é sempre uma construção: "não a forma encontrada [...] mas a forma atingida" 
(Cabral 1994: 95). Ao mesmo tempo, como indica a voz poética, "há qualquer coisa de 'des' na palavra construção", apontando mais uma vez para uma convergência entre aparentes opostos: "uma construção pode bem ser o lado avesso de uma tristezura" (Ondjaki 2009: 59), conforme sugerido em outro texto. Desta forma o poema seria também uma

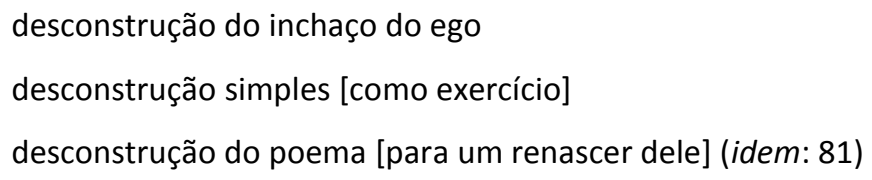

Ao se revelar hibridamente como uma construção inseparável do seu "avesso" (uma "desconstrução"), a poesia nasce, como indica o poema "Essa palavra margem", não na interioridade do poeta, mas num espaço liminar, uma espécie de terceira margem, para usarmos a expressão notabilizada por Guimarães Rosa (um dos mestres de Ondjaki) ${ }^{3}$, entre o eu e o não eu. Em outras palavras, ela não remete a uma dimensão transcendente, mas se origina do confronto do eu com, citando novamente Drummond, o "mundo, mundo, vasto mundo" (Andrade 2003: 5), isto é, os objetos e outros seres humanos ao seu redor: "minha margem / na margem / do meu poema" (Ondjaki 2009: 79). Uma permanente condição de marginalidade é fundamental à poesia porque esta nasce, como foi sugerido acima, num entrelugar; ela é por excelência liminal. Mas a poesia também é marginal porque se origina na carnavalização - para recorrermos à terminologia bakhtiniana - do que é geralmente considerado normal ou oficial ("poeta à margem / poesia das margens / margem de gente / à margem da vida" (idem: 78)). Intrínseca à poesia, a marginalidade cria a possibilidade de uma utopia que desconstrói os rígidos binarismos em que se fundamenta o mundo individualista, racional e utilitário: "a confecção de poemas a partir de fiapos inconcretos é uma arte diferente da feitura de almofadas, até porque as almofadas podem ainda ter utilidade apalpável" (idem: 66-67). Desta maneira, a poesia abriria as portas de uma realidade mais fluida e generosa, para além dos limites do indivíduo conforme este é concebido pela modernidade racional e iluminista. Para usarmos a terminologia clássica de Martin Buber (1970: 56), a poesia assim concebida aponta para um "mundo da relação", diferentemente do "mundo como experiência": "a poesia é a cauda do dragão invisível que une as pessoas ao fogo da grande ardósia" (Ondjaki 2009: 69). 
Esse "mundo da relação" se revela, entre outras coisas, nas transações entre o humano e o natural. Para Ondjaki, ao contrário dos românticos, a relação entre o ser humano e a natureza não aponta para o sublime. No poema em prosa "Manipular a grande ardósia", o autor retorna ao personagem João Vêncio, de Luandino Vieira, para delinear um ser humano que, diante da natureza, experimenta não o espanto radical diante do "sublime", de que fala Kant, mas uma continuidade entre os seres humanos e o mundo natural: "tropeçando entre as estrelas, dois compadres se abraçavam em bebedeira: maisvelho e joão vêncio, o triste e o melancólico, apertavam a noite nesse abraço [a imaginária imagem do foro do senhor chaplin]" (idem: 24). Nesse mundo desierarquizado, onde é possível "fazer o joão vêncio pontapear uma estrela apagada até ela se acender de novo", postula-se uma ética alternativa, marginal e contestatória, pois "manejando a ardósia do universo, tudo poderia ser alterado" (ibidem). Ecoando a "poesia mineral" de João Cabral, numa passagem do poema em prosa "Pequeno espanador de tristezas", que dá título ao volume, o poeta propõe uma espécie de receita para um encontro menos conflituoso e mais produtivo entre o eu e o mundo: "vou encher-me de silêncios e imitar as pedras. adormecer entre pedras pode ser que me contagie delas. depois de conseguir ser pedra vou exercitar o sorriso dessa pedra que eu for. com esse sorriso vou iniciar uma construção..." (idem: 59).

O tema de um universo reconcebido para além dos dualismos e hierarquias que regem o pensamento ocidental é retomado em "Confissões", no qual o sublime de Kant, racional e europeu, separando a natureza objetiva da mente subjetiva, é "africanizado" pela cumplicidade afetiva e intersubjetiva entre a música da natureza e a música improvisada pelo compositor de jazz: "aqui é luanda - terra das gentes várias e o carnaval das árvores, de noite um grilo-de-trepadeiras me faz companhia e, sem saber, divide orquestra com o chet baker, when I go to his head." (idem: 40). Significativamente, o poema conclui imaginando um encontro igualitário entre seres humanos e animais: "um dia vou contracenar com um gafanhoto, um pirilampo, um gambozino, um grilo e uma andorinha aqui na minha varanda dos vasos bonitos. se o chet aceitar tocar trompeta, eu vou ser a assistência toda - o xaxualhar dos olhos ouvintes" (idem: 40).

No capítulo "Reopening the question of the human and the animal", em History and its Limits, Dominick LaCapra reflete sobre algumas dessas questões em termos que acredito 
serem úteis à presente discussão. LaCapra propõe que a cultura ocidental depende, em grande parte, da viabilidade de uma rígida oposição entre os seres humanos e os outros animais (e por extensão o resto da natureza), isto é, entre humanidade e animalidade:

The very notion of human being seems typically to rely on an essentializing figuration or conception of humanity whereby the essence or very being of the human 'as such' is its humanness in contrast to the animality of the animal. (LaCapra 2009: 155)

[“A própria noção de ser humano parece tipicamente basear-se em uma figuração essencializante ou em uma concepção da humanidade na qual a essência ou o próprio ser do humano 'como tal' é a sua humanidade em contraste com a animalidade do animal"]

Essa ideia derivaria de uma concepção do ser humano como única e exclusivamente criado à imagem de Deus, essencial à tradição judaico-cristã. LaCapra desenvolve o seguinte argumento:

It is significant to note that in Kant, there is an appeal to a presumably universalistic but discriminatory conception of ethics in the argument that morality itself is what separates "man", as a being with access to the sublime, from the rest of nature. Here the Kantian sublime, which may perhaps be seen as a displacement of the sacred, serves in its linkage with morality as a decisive criterion separating humans from, and elevating them above, the rest of nature. (idem: 156)

[É significativo notar que, em Kant, há um apelo a uma concepção presumivelmente universalista mas discriminatória da ética no argumento de que a própria moralidade é o que separa o "homem", como um ser com acesso ao sublime, do resto da natureza. Aqui, o sublime kantiano, que talvez possa ser visto como um deslocamento do sagrado, serve em sua ligação com a moralidade como um critério decisivo que separa os seres humanos e os eleva acima do resto da natureza.]

Ondjaki, todavia, não concebe o humano como elemento privilegiado. Sua visão dialoga, antes, com a concepção generosa e ao mesmo tempo transgressora do mundo que identificamos em São Francisco de Assis. ${ }^{4}$

\section{Conclusão}

Em seu revisionismo marxista, Michael Hardt e Antonio Negri releem, numa linha semelhante à de LeGoff, o pensamento de São Francisco de Assis como uma rejeição do 
individualismo essencial ao capitalismo então nascente, na medida em que Francisco substitui a mortificação da carne e a estabilidade da ordem constituída pela alternativa de uma vida feliz e espontânea porque perfeitamente integrada com o resto da natureza, lição que, segundo aqueles autores, se aplicaria igualmente à pós-modernidade:

Once again in postmodernity we find ourselves in Francis's situation, posing against the misery of power the joy of being. This is a revolution that no power will control - because biopower and communism, cooperation and revolution remain together, in love, simplicity, and also innocence. This is the irrepressible lightness and joy of being communist. (Hardt/Negri 2004: 413)

[Mais uma vez, na pós-modernidade, nos encontramos na situação de Francisco, colocando contra a miséria do poder a alegria de ser. Esta é uma revolução que nenhum poder controlará - porque o biopoder e o comunismo, a cooperação e a revolução permanecem juntos, no amor, na simplicidade e também na inocência. Esta é a irreprimível leveza e alegria de ser comunista.]

De sua parte LaCapra, em sua peremptória defesa dos direitos dos animais, rejeita a leitura do pensamento de São Francisco, empreendida por Hardt e Negri, como excessivamente antropocêntrica, argumento que considero contestável mas que certamente complicaria algumas ideias desenvolvidas neste artigo: "For the questioning of a decisive criterion separating the human from the animal or even from the rest of nature has widespread ramifications, indicating the need for a major paradigm shift in the relations of the human, the animal, and nature in general" ["Pois o questionamento de um critério decisivo que separasse o humano do animal ou mesmo do resto da natureza tem amplas ramificações, indicando a necessidade de uma grande mudança de paradigma nas relações do humano, do animal e da natureza em geral"] (La Capra 2009: 189). O que é inegável, contudo, é que a alternativa transgressora que Hardt e Negri identificam ao refletirem sobre a comunidade generosa de Francisco nos ajuda a reconhecer no hibridismo de Ondjaki uma forma de contestação, que aponta para uma existência orgânica, comunal e desierarquizada, além das divisões do mundo contemporâneo, com suas especializações e polarizações. Conforme propôs Leibniz, a generosidade, herdada de nossas origens no divino, é fundamental à existência de uma república universal em que a lei suprema seria buscar o máximo de bem possível para todos. E, voltando ao anteriormente citado Martin Buber, os seres humanos não são indivíduos autônomos, operando de acordo com regras abstratas e 
impessoais, mas interconectados por uma reciprocidade essencial. Na sua transgressão de limites impostos pela civilização racional - utilitária e iluminista -, hibridismo e generosidade se articulam e se completam.

Como sugerimos anteriormente, os pensadores que refletiram sobre a generosidade, com os quais relacionamos a poesia híbrida de Ondjaki, demonstram um forte substrato teológico: São Francisco, Leibniz, Buber, São Paulo, Freire, Boff (ele mesmo um exfranciscano) etc. A obra de Ondjaki revela preocupações semelhantes sem subscrever, contudo, qualquer forma de religiosidade tradicional. Aqui religião só poderia ser pensada no sentido etimológico da palavra como ligação ou conexão. Poderíamos dizer que se trata de uma religiosidade laica e dessacralizada. Nesse sentido, assemelha-se à "poética da generosidade", que propus em meu ensaio sobre Carlos Drummond de Andrade e William Carlos Williams referido acima. Não deve surpreender que o tópico tenha atraído a atenção de poetas de extirpe progressista como Drummond e Williams, bem como de renovadores marxistas como Hardt e Negri, que colocam em questão o individualismo exacerbado da cultura ocidental desde o advento do capitalismo.

Em uma célebre passagem de Grande Sertão: Veredas, de Guimarães Rosa, aliás um dos livros de cabeceira de Ondjaki, o protagonista-narrador Riobaldo propõe que "a vida é mutirão de todos, por todos remexida e inventada" (Rosa 1972: 348), onde tudo e todos estão inevitavelmente interconectados. Com sua fundamental dissidência, a poesia híbrida e generosa de Ondjaki parece compreender e se identificar com essa proposição. 


\section{NOTAS}

1 "As Seneca describes him, the noble person values virtue, or rectitude, for its own sake and above all else. Consequently, he is secure against hardships of fortune that threaten external goods, such as wealth or fame. For Seneca, such an individual is truly generosus, or well born; and for both Stoics and later Christians, it was natural to regard such individuals as approaching most closely their divine origin" (Rutherford 2002: 15).

[“Como Sêneca a descreve, a pessoa nobre valoriza a virtude, ou retidão, por si mesma e acima de tudo. Consequentemente, está segura contra as dificuldades da fortuna que ameaçam bens externos, como riqueza ou fama. Para Sêneca, tal indivíduo é verdadeiramente generoso, ou bem nascido; e tanto para os estoicos quanto, mais tarde, para os cristãos, era natural considerar tais indivíduos como se aproximando mais de perto de sua origem divina"].

${ }^{2}$ Note-se que, juntamente com a doutrina paulina, a teologia franciscana foi apropriada por Paulo Freire ao mesclar a crença cristã com a práxis marxista em sua Pedagogia do Oprimido, que poderia ser descrita como uma variação politicamente engajada do tema generosidade.

${ }^{3} \mathrm{Em}$ nota de rodapé o poeta escreve, com uma mistura de respeito e ironia, que "quem quase domesticou a palavra margem foi guimarães rosa..." (Ondjaki 2009: 78).

${ }^{4}$ Na sua magistral biografia de São Francisco de Assis, o historiador francês Jacques Le Goff (1924-2014) concebe Francisco principalmente como um reformador, que teria demonstrado uma profunda consciência das contradições e conflitos da sociedade italiana de seu tempo, e que supostamente teria sido angustiado pelas mudanças trazidas pelo desenvolvimento de uma economia monetária. 


\section{Bibliografia}

Andrade, Carlos Drummond de (2003), Poesia completa, Rio, Nova Aguilar.

Buber, Martin (1970), I and Thou, tradução Walter Kaufmann, NY, Scribner's.

Freire, Paulo (1970), Pedagogia do Oprimido, Rio, Paz e Terra.

Hardt, Michael / Antonio Negri (2004), Multitude. War and democracy in the age of empire, NY, Penguin.

Kant, Immanuel (1972), Critique of Judgement, tradução J. H. Bernard, NY, Hafner.

LaCapra, Dominick (2009), History and its Limits. Human, animal, violence, Ithaca, Cornell U Press.

Le Goff, Jacques (1999), Saint François d'Assise, Paris, Gallimard.

Leibniz, Gottfried Wilhelm (2002), "On generosity”, The Leibniz Review, tradução Donald Rutherford, vol. 12: 18-20 [1686-1687?].

Melo Neto, João Cabral de (1985), Obra Completa, Rio, Nova Aguilar.

Nascentes, Antenor (1966), Dicionário Etimológico Resumido, Rio, INL.

Ondjaki (2009), Materiais para Confecção de um Espanador de Tristezas, Alfragide, Caminho. Paul, Saint (s/d), "Epistle to the Phillipians", in The Holy Bible: King James version, NY, World Publishing Company: 147-158.

-- (s/d), "First epistle to the Corinthians", in The Holy Bible: King James version, NY, World Publishing Company: 174-176.

Rosa, João Guimarães (1972), Grande Sertão: Veredas, 8. a ed, Rio, José Olympio.

Rutherford, Donald (2002), “Leibniz's 'On Generosity', with English translation”, The Leibniz Review, vol. 12: 15-17.

Valente, Luiz Fernando (2005), "William Carlos Williams and Carlos Drummond de Andrade: a poetics of generosity", Ellipsis 3: 7-19. 
Weber, Max (2001), The Protestant Ethic and the Spirit of Capitalism, tradução Talcott Parsons, NY, Routledge.

Luiz Fernando Valente é professor titular de Estudos Portugueses e Brasileiros e de Literatura Comparada na Brown University (EUA). É autor de Mundivivências. Leituras comparativas de Guimarães Rosa, história e fiç̧ão. Convergências e contrastes, e cerca de oitenta capítulos de livros coletivos e artigos em revistas científicas nos Estados Unidos, Brasil e Portugal. Foi diretor do Departamento de Estudos Portugueses e Brasileiros da Brown University (2003-2012) e presidente da American Portuguese Studies Association (2013-2015). É coeditor de Brasil/Brazil. A journal of Brazilian literature, fundada em 1988 em parceria com colegas da Universidade Federal do Rio Grande do Sul (Brasil). 